\title{
BMJ Open Do parents play different roles in drinking behaviours of male and female adolescents? A longitudinal follow-up study
}

\author{
Chao-Chia Hung, ${ }^{1}$ Hsing-Yi Chang, ${ }^{2}$ Dih-Ling Luh, ${ }^{3,4}$ Chi-Chen Wu, ${ }^{2}$ \\ Lee-Lan Yen ${ }^{2,5}$
}

To cite: Hung $C-C$ Chang H-Y, Luh D-L, et al. Do parents play different roles in drinking behaviours of male and female adolescents? A longitudinal follow-up study. BMJ Open 2015; : $: 007179$ doi:10.1136/bmjopen-2014007179

- Prepublication history for this paper is available online. To view these files please visit the journal online (http://dx.doi.org/10.1136/ bmjopen-2014-007179).

Received 12 November 2014 Revised 11 March 2015 Accepted 20 March 2015

CrossMark

For numbered affiliations see end of article.

Correspondence to Dr Hsing-Yi Chang; hsingyi@nhri.org.tw

\section{ABSTRACT}

Objective: Gender differences in the associations between adolescent drinking behaviour, and perceived parental drinking behaviours and attitudes towards underage drinking, were investigated.

Methods: Data were drawn from two cohorts in the Child and Adolescent Behaviours in Long-term Evolution project. We used data from 2009 to 2006 , when cohorts 1 and 2, respectively, were in grade 9 . No cohort effect was found, so the two cohorts were pooled; 3972 students (1999 boys and 1973 girls) participated in the study. The major variables included adolescent drinking behaviours over the last month, and perceived parental drinking behaviours and parental attitudes towards underage drinking. The effects of the combination of parental drinking behaviours, and attitudes on the drinking behaviours of male and female adolescents, were analysed by logistic regression.

Results: The drinking behaviour of boys was correlated with the drinking behaviours and attitudes of their fathers but not with those of their mothers. Among boys, having a non-drinking father who was against underage drinking ( $\mathrm{OR}=0.27,95 \% \mathrm{Cl} 0.16$ to 0.46 ), a non-drinking father who was favourable towards underage drinking ( $\mathrm{OR}=0.61,95 \% \mathrm{Cl} 0.39$ to 0.94$)$, or a drinking father who was against underage drinking (OR=0.44, $95 \% \mathrm{Cl} 0.23$ to 0.85 ) significantly decreased the likelihood of alcohol consumption, whereas maternal behaviour and attitude were not significant influences. Among girls, having a non-drinking father who was against underage drinking $(\mathrm{OR}=0.52,95 \% \mathrm{Cl}$ 0.30 to 0.91 ) or a non-drinking father who was favourable towards underage drinking $(\mathrm{OR}=0.51,95 \%$ $\mathrm{Cl} 0.32$ to 0.83 ) significantly decreased the likelihood of alcohol consumption, as did having a non-drinking mother who was against underage drinking $(\mathrm{O} R=0.23$, $95 \% \mathrm{Cl} 0.09$ to 0.60 ).

Conclusions: The influences of fathers and mothers on the drinking behaviour of their adolescent children differed by offspring gender.

\section{INTRODUCTION}

Underage drinking is a social and public health issue that receives much attention.

\section{Strengths and limitations of this study}

- This study considered the effects of the combination of parental drinking behaviours and attitudes on the drinking behaviours of male and female students.

- This study pooled two cohorts and examined the influence of parental behaviours and attitudes on the drinking behaviours of male and female students.

- This study considered only drinking behaviour over the last month and did not consider amount or frequency of alcohol use.

- Parental drinking behaviours and attitudes were reported by adolescents rather than by parents.

Drinking behaviour differs significantly across gender. The stages in the developmental trajectories of various drinking behaviours occur earlier among males than among females, and drinking frequency and amount of alcohol consumed are higher among males. ${ }^{1}$ Recently, however, gender convergence in the drinking behaviours of adolescents has been reported. ${ }^{23}$ Because of the modern emphasis on gender mainstreaming, paying attention to the relevant factors associated with drinking behaviours across gender can be expected to facilitate the development of appropriate strategies for preventing adolescent drinking.

Multiple factors influence drinking behaviour, and the family plays an important role with regard to adolescent drinking behaviour. Family members, especially parents, affect the substance use of adolescents. ${ }^{4}$ The drinking behaviours of parents and their attitudes towards underage drinking are both associated with alcohol use among adolescents. ${ }^{5}$ Many studies have shown that children are more likely to drink if both parents are drinkers, rather than if only one or neither drink. ${ }^{6-8}$ Various indicators of 
adolescent alcohol use, including age at first alcohol use, lifetime alcohol use, alcohol use over the last year, alcohol use over the last month and excess alcohol use, are associated with parental drinking behaviour. Child-reported levels of parental drinking have been reported to be significantly associated with alcohol drinking in children. ${ }^{9}$ However, studies of the individual influences of paternal and maternal drinking behaviours on the drinking behaviours of their male and female children have not shown consistent results. For example, $\mathrm{Yu}$ and Perrine ${ }^{10}$ reported that paternal drinking behaviours influence the drinking behaviours of sons, whereas maternal drinking behaviours influence those of daughters. Other investigators have argued that the influence of maternal drinking behaviours on children's drinking behaviours is greater than that of paternal drinking behaviours, ${ }^{11-13}$ and $\mathrm{Yeh}^{14}$ reported that fathers significantly influence the excessive drinking behaviours of their children, whereas mothers have no influence. However, most studies argue that parental alcohol use increases the likelihood of alcohol use in children, although Haugland et $a l^{15}$ found that male adolescents with alcohol-abusing mothers were less likely to use alcohol to excess than were male adolescents whose mothers did not abuse alcohol. Overall, these studies consistently emphasise that the individual drinking problems of parents influence the drinking problems of their male and female children.

Kelly et $a l^{16}$ argued that parental attitudes towards underage drinking influence the drinking behaviours of their children (regardless of offspring gender), whether the attitudes were clearly articulated during a discussion of drinking behaviour or during the development of rules to restrict alcohol use. Van der Vorst et $a l^{17}$ reported that the outcomes of discussions between adolescents and their parents about drinking behaviours differ by gender: males are significantly influenced, whereas females are not. Other studies have indicated that parental restrictions on adolescent alcohol use can delay the start of alcohol use among adolescents, can decrease the frequency and amount of alcohol consumption, ${ }^{18-21}$ and can delay the development of harmful drinking behaviours. ${ }^{21}$ However, the aforementioned studies did not distinguish fathers from mothers. A study that did distinguish between the effects of paternal and maternal attitudes about underage drinking on the drinking behaviours of their underage children at different ages showed that paternal drinking rules significantly delay alcohol use among younger children, whereas maternal attitudes do not have the same effect. ${ }^{19}$

The drinking behaviours of parents are associated with their attitudes towards underage drinking. Compared to parents who do not drink, parents who drink usually have more-relaxed rules with regard to underage drinking. ${ }^{19-23}$ Most of the previous studies of parental drinking behaviours and attitudes regarded these variables as independent, and introduced them into joint models or used one of them as a mediator. No previous study has examined the relationship between adolescent drinking behaviours and parental drinking behaviours, and attitudes towards underage drinking.

In summary, previous studies of the effects of parental drinking behaviours and attitudes towards underage drinking on adolescent drinking behaviours have the following limitations. First, previous studies have not adequately considered the various same-gender, and cross-gender, interactions of paternal and maternal drinking behaviours and attitudes, with the drinking behaviours of male and female children. Moreover, previous studies focused on geographical areas with a high prevalence of alcohol use in Europe and the Americas. In developed countries, underage drinking behaviour, which has long been a concern, has recently begun to decrease. ${ }^{24} 25$ Interestingly, the wine industry has begun to focus its marketing efforts on Western Pacific countries with developed economies and low rates of alcohol consumption. ${ }^{26}$ Taiwan is in this region; therefore, investigation of Taiwanese data on the parental factors that affect underage drinking behaviour can help to establish an effective mechanism for preventing underage drinking in areas with low rates of alcohol consumption. On the basis of a review of the above-described literature, the major purpose of this study was to investigate the drinking behaviours of male and female ninth grade students in Taiwan, and the association of these behaviours with parental drinking behaviours and attitudes, simultaneously.

\section{METHODS}

\section{Study population}

The data used in this study were obtained from the Child and Adolescent Behaviours in Long-term Evolution (CABLE) project. $^{27}$ The present study included two cohorts: cohort 1 consisted of 2719 students who were in the first grade in 2002 (when the study began) and were in the ninth grade (14-15 years old) in 2009; and cohort 2 consisted of 2499 students who were in the fifth grade (10-11 years old) in 2002 and were in the ninth grade (14-15 years old) in 2006. Participants with missing data were excluded, resulting in a final sample of 1961 students in cohort $1(72.12 \%)$ and 2011 students in cohort 2 $(80.47 \%)$. The $\chi^{2}$ test was used to assess differences from baseline with regard to sex and residential area. No significant differences were found between the samples.

Since the CABLE project is school based, clustering effects on adolescent drinking behaviour had to be taken into account. Therefore, we used a general estimating equation with an exchangeable working correlation matrix to investigate the presence of clustering effects. The obtained correlation coefficients of -0.002 for cohort 1 and -0.003 for cohort 2 for both models indicated that the correlation of current drinking behaviours among adolescents within each school was low. Therefore, we ignored clustering effects and analysed the data as an independent sample. 


\section{Measures}

\section{Student drinking behaviour}

Students reported the frequency of their alcohol use by answering the question 'Have you ever used alcohol?' using a six-point scale: $1=$ never used; $2=$ not over the last year, but have used before; $3=$ not over the last month, but have used before; $4=$ used once or twice over the last month; $5=$ have used many times over the last month and $6=$ have used every day over the last month. On the basis of their responses, the students were combined into two groups as follows: scores of 1-3 were recoded as $1=$ nondrinking and scores of 4-6 were recoded as $2=$ used over the last month.

\section{Student-reported paternal and maternal drinking behaviours and attitudes}

Students reported their perceptions of the drinking frequencies of their fathers and mothers by using a sixpoint scale in response to the questions 'Does your father use alcohol?' and 'Does your mother use alcohol?': 1=never; $2=$ not over the last year, but has used before; $3=$ not over the last month, but has used before; $4=$ has used once or twice over the last month; $5=$ has used several times over the last month and $6=$ has used every day over the last month. Scores of 1-4 were recoded as $1=$ used infrequently and scores of 5-6 were recoded as $2=$ used frequently.

Students also reported their perceptions of the attitudes of their parents towards underage drinking on a five-point scale in response to the prompts 'Your father's attitude towards your alcohol use' and 'Your mother's attitude towards your alcohol use': 1=very against, $2=$ against, $3=$ no opinion, $4=$ favourable, and $5=$ very favourable. Scores of 1-2 were recoded as $0=$ against and scores of 3-5 were recoded as $1=$ favourable.

Finally, perceived paternal drinking frequencies and attitudes were combined into four categories, and recoded as follows: (1) NDA, non-drinking and against underage drinking; (2) NDF, non-drinking but favourable towards underage drinking; (3) DA, drinking frequently but against underage drinking and (4) DF, drinking frequently and favourable towards underage drinking. Maternal drinking behaviours and attitudes were categorised, and coded in the same way.

\section{Background variables}

Relevant background variables with regard to underage drinking based on previous studies were controlled, ${ }^{6} 1428-33$ including cohort factors, age at first alcohol use, residential area, parental marital status, parental education level, parenting behaviour (ie, degrees of emotional support and behaviour supervision), peer alcohol use, peer pressure with regard to alcohol use, alcohol expectancies and alcohol refusal efficacy.

\section{Statistical analysis}

We first used SAS V.9.1 to perform a descriptive statistical analysis on the data across gender using the distribution of the mean, percentages, and SDs for the independent and the dependent variables. Next, we compared the independent and dependent variables, for males and females, using $\chi^{2}$ and analysis of variance, to determine differences. Finally, we constructed models of the total sample, as well as male and female student samples, and analysed the factors that influenced the drinking behaviour of the adolescents by using logistic regression.

\section{RESULTS}

The study population comprised 3972 students (1999 males and 1973 females; tables 1 and 2). Of these students, 679 reported having consumed alcohol over the last month. More males than females consumed alcohol over the last month. Adolescents with fathers who were non-drinkers and against underage drinking comprised the majority of the sample (55.74\%), followed by adolescents with fathers who were non-drinkers but favoured underage drinking $(29.51 \%)$; the corresponding percentages for the mothers were $68.05 \%$ and $29.68 \%$, respectively. Paternal drinking behaviour and attitude differed significantly by gender: more females than males had fathers who were NDA $(57.78 \%$ vs $53.73 \%)$ or DA $(8.01 \%$ vs $7.15 \%)$. Conversely, more males than females had fathers who were NDF $(31.62 \%$ vs $27.37 \%)$ or DF $(7.50 \%$ vs $6.84 \%)$. In other words, fathers were more against alcohol use by their daughters than by their sons. The effects of maternal drinking behaviour and attitude did not significantly differ by offspring gender.

We conducted logistic regression analysis of the drinking behaviour-related factors across all participants and observed the following results with regard to the factors related to adolescent alcohol consumption over the last month (table 3). Comparison between adolescents whose fathers were DF and adolescents whose fathers were NDA, NDF and DA resulted in ORs and 95\% CIs of 0.36 (0.25 to 0.52$), 0.57$ (0.41 to 0.78$)$ and 0.46 (0.28 to 0.75$)$, respectively. Compared with adolescents whose mothers were DF, those whose mothers were NDA $(\mathrm{OR}=0.33 ; 95 \%$ CI 0.17 to 0.65$)$ or $\mathrm{NDF}(\mathrm{OR}=0.49 ; 95 \%$ CI 0.25 to 0.94 ) were significantly less likely to consume alcohol.

The results of logistic regression analysis of the drinking behaviour-related factors across gender showed that male adolescents whose fathers were NDA (OR $=0.27$; $95 \%$ CI 0.16 to 0.46$)$, NDF ( $\mathrm{OR}=0.61 ; 95 \%$ CI 0.39 to 0.94 ) or DA (OR=0.44; $95 \%$ CI 0.23 to 0.85 ) were significantly less likely to consume alcohol than those whose fathers were DF. Paternal drinking behaviour and attitude influenced male adolescent drinking behaviour, whereas maternal drinking behaviour and attitude did not. In addition, cohort 2 was more likely to consume alcohol than cohort 1 (OR=1.51; 95\% CI 1.15 to 1.98$)$. Male adolescents were more likely to have used alcohol over the last month when the first alcohol use occurred before age 13 ( $\mathrm{OR}=2.16$; 95\% CI 1.63 to 2.88$)$, when perceived positive alcohol expectancies increased one 
Table 1 Distribution of variables by adolescent gender

\begin{tabular}{|c|c|c|c|c|}
\hline Variable & $\begin{array}{l}\text { Total sample } \\
\text { Number of } \\
\text { people (\%) }\end{array}$ & $\begin{array}{l}\text { Males } \\
\text { Number of } \\
\text { people (\%) }\end{array}$ & $\begin{array}{l}\text { Females } \\
\text { Number of } \\
\text { people (\%) }\end{array}$ & $\chi^{2} / \mathrm{F}$ \\
\hline \multicolumn{5}{|l|}{ Drinking over the last month } \\
\hline No & 3293 (82.91) & $1630(81.54)$ & $1663(84.29)$ & $5.29^{*}$ \\
\hline Yes & 679 (17.09) & 369 (18.46) & $310(15.71)$ & \\
\hline Perceived paternal drinking behaviour/attitude & & & & $10.56^{*}$ \\
\hline NDA & $2214(55.74)$ & $1074(53.73)$ & $1140(57.78)$ & \\
\hline NDF & $1172(29.51)$ & 632 (31.62) & $540(27.37)$ & \\
\hline DA & $301(7.58)$ & $143(7.15)$ & $158(8.01)$ & \\
\hline DF & $285(7.18)$ & $150(7.50)$ & $135(6.84)$ & \\
\hline Perceived maternal drinking behaviour/attitude & & & & 0.62 \\
\hline NDA & $2703(68.05)$ & $1354(67.73)$ & $2703(68.37)$ & \\
\hline NDF & 1179 (29.68) & 602 (30.12) & $1179(29.24)$ & \\
\hline DA & $39(0.98)$ & $18(0.90)$ & $39(1.06)$ & \\
\hline DF & $51(1.28)$ & $25(1.25)$ & $51(1.32)$ & \\
\hline \multicolumn{5}{|l|}{ Cohort } \\
\hline Cohort 1 & 1961 (49.37) & 976 (48. 82) & 985 (49.92) & 0.48 \\
\hline Cohort 2 & $2011(50.63)$ & $1023(51.18)$ & $988(50.08)$ & \\
\hline \multicolumn{5}{|l|}{ Age at first alcohol use (years) } \\
\hline$<13$ & 917 (23.09) & $443(22.16)$ & 474 (24.02) & 1.94 \\
\hline$\geq 13$ & 3055 (76.91) & $1556(77.84)$ & 1499 (75.98) & \\
\hline
\end{tabular}

Table 2 Distribution of variables by gender

\begin{tabular}{|c|c|c|c|c|}
\hline Variable & $\begin{array}{l}\text { Total sample } \\
\text { Number of } \\
\text { people (\%) } \\
\text { or mean (SD) }\end{array}$ & $\begin{array}{l}\text { Males } \\
\text { Number of } \\
\text { people (\%) } \\
\text { or mean (SD) }\end{array}$ & $\begin{array}{l}\text { Females } \\
\text { Number of } \\
\text { people (\%) } \\
\text { or mean (SD) }\end{array}$ & $\chi^{2} / F$ \\
\hline \multicolumn{5}{|l|}{ Residential area } \\
\hline Taipei & 2052 (51.66) & $1010(50.53)$ & $1042(52.81)$ & \multirow[t]{2}{*}{2.08} \\
\hline Hsinchu county & $1920(48.34)$ & 989 (49.47) & 931 (47.19) & \\
\hline \multicolumn{5}{|l|}{ Parental marital status } \\
\hline Married, living together & 3650 (91.89) & $1847(92.40)$ & $1803(91.38)$ & \multirow[t]{2}{*}{1.37} \\
\hline Other & $322(8.11)$ & $152(7.60)$ & 170 (8.62) & \\
\hline \multicolumn{5}{|l|}{ Paternal education level } \\
\hline Middle school or lower & 589 (14.83) & $305(15.26)$ & $284(14.39)$ & \multirow[t]{3}{*}{2.84} \\
\hline High school & 1407 (35.42) & $683(34.17)$ & $724(36.70)$ & \\
\hline College or higher & 1976 (49.75) & $1011(50.58)$ & 965 (48.91) & \\
\hline \multicolumn{5}{|l|}{ Maternal education level } \\
\hline Middle school or lower & $571(14.38)$ & $292(14.61)$ & $279(14.14)$ & \multirow[t]{3}{*}{5.94} \\
\hline High school & $1797(45.24)$ & 867 (43.37) & $930(47.14)$ & \\
\hline College or higher & $1604(40.38)$ & $840(42.02)$ & 764 (38.12) & \\
\hline \multicolumn{5}{|l|}{ Parenting behaviour } \\
\hline Degree of emotional support (6-24 points) & $17.06(4.81)$ & $16.74(4.81)$ & $17.38(4.78)$ & $17.56^{\star \star \star}$ \\
\hline Degree of behavioural supervision (4-16 points) & $13.37(2.89)$ & $13.21(2.96)$ & $13.52(2.81)$ & $12.29^{* *}$ \\
\hline Positive alcohol expectancies (5-20 points) & $9.72(3.26)$ & $13.04(3.98)$ & $14.13(3.34)$ & $8.16^{\star \star}$ \\
\hline Negative alcohol expectancies (5-20 points) & $13.58(3.72)$ & $20.99(5.68)$ & $21.50(4.75)$ & $88.48^{\star * \star}$ \\
\hline Alcohol refusal efficacy (5-25 points) & $21.25(5.24)$ & $1.84(0.87)$ & $1.77(0.82)$ & $9.31^{\star *}$ \\
\hline Peer alcohol use (2-10 points) & $1.82(0.85)$ & $1.84(0.87)$ & $1.77(0.82)$ & $7.38^{\star *}$ \\
\hline Alcohol use peer pressure (2-12 points) & $1.23(0.75)$ & $9.87(3.47)$ & $9.57(3.02)$ & $6.03^{*}$ \\
\hline
\end{tabular}


Table 3 Logistic regression analysis of drinking behaviour of all participants with regard to parental drinking behaviours and attitudes as well as others factors

\begin{tabular}{|c|c|c|c|}
\hline Variable & OR & $95 \% \mathrm{Cl}$ & p Value \\
\hline \multicolumn{4}{|l|}{ Perceived paternal drinking behaviour/attitude } \\
\hline NDA vs DF & 0.36 & 0.25 to 0.52 & 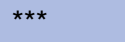 \\
\hline NDF vs DF & 0.57 & 0.41 to 0.78 & $* * *$ \\
\hline DA vs DF & 0.46 & 0.28 to 0.75 & ** \\
\hline \multicolumn{4}{|l|}{ Maternal drinking behaviour/attitude } \\
\hline NDA vs DF & 0.33 & 0.17 to 0.65 & ** \\
\hline NDF vs DF & 0.49 & 0.25 to 0.94 & * \\
\hline DA vs DF & 0.64 & 0.22 to 1.84 & \\
\hline \multicolumn{4}{|l|}{ Cohort } \\
\hline 1 vs 2 & 1.65 & 1.36 to 2.00 & $\star * *$ \\
\hline \multicolumn{4}{|l|}{ Gender } \\
\hline Male vs female & 1.03 & 0.85 to 1.25 & \\
\hline \multicolumn{4}{|l|}{ Age at first alcohol use } \\
\hline$<13$ vs $\geq 13$ years & 2.27 & 1.85 to 2.77 & $\star * *$ \\
\hline \multicolumn{4}{|l|}{ Residential area } \\
\hline Hsinchu county vs Taipei & 1.01 & 0.82 to 1.24 & \\
\hline \multicolumn{4}{|l|}{ Parental marital status } \\
\hline Married, living together vs other & 0.89 & 0.64 to 1.24 & \\
\hline \multicolumn{4}{|l|}{ Paternal education level } \\
\hline Middle school or below vs college or above & 1.28 & 0.90 to 1.82 & \\
\hline High school vs college or above & 1.25 & 0.97 to 1.61 & \\
\hline \multicolumn{4}{|l|}{ Maternal education level } \\
\hline Middle school or below vs college or above & 0.84 & 0.58 to 1.21 & \\
\hline High school vs college or above & 0.82 & 0.64 to 1.06 & \\
\hline \multicolumn{4}{|l|}{ Parenting behaviour } \\
\hline Degree of emotional support (6-24 points) & 1.01 & 0.99 to 1.04 & \\
\hline Degree of behavioural supervision (4-16 points) & 0.98 & 0.95 to 1.02 & \\
\hline \multicolumn{4}{|l|}{ Cognitive factors } \\
\hline Positive alcohol expectancies (5-20 points) & 1.07 & 1.04 to 1.11 & $\star * *$ \\
\hline Negative alcohol expectancies (5-20 points) & 0.92 & 0.89 to 0.95 & $\star \star \star *$ \\
\hline Alcohol refusal efficacy (5-25 points) & 0.95 & 0.93 to 0.97 & $\star * *$ \\
\hline \multicolumn{4}{|l|}{ Peer factors } \\
\hline Peer alcohol use (2-10 points) & 1.66 & 1.49 to 1.85 & $\star * *$ \\
\hline Alcohol use peer pressure (2-12 points) & 1.36 & 1.22 to 1.51 & $\star \star \star *$ \\
\hline
\end{tabular}

point (OR=1.10; 95\% CI 1.05 to 1.16$)$, when negative alcohol expectancies decreased one point $(\mathrm{OR}=0.92$ $95 \%$ CI 0.88 to 0.96$)$, when alcohol refusal efficacies decreased one point ( $\mathrm{OR}=0.96$; $95 \%$ CI 0.94 to 0.98$)$, when more peers were perceived as using alcohol $(\mathrm{OR}=1.81 ; 95 \%$ CI 1.57 to 2.10$)$ and when peer pressure regarding alcohol use was stronger $(\mathrm{OR}=1.45 ; 95 \%$ CI 1.26 to 1.66$)$.

Table 4 also shows the results from the analysis of the drinking behaviour-related factors with regard to female adolescents. Compared with females whose fathers were $\mathrm{DF}$, those whose fathers were NDA $(\mathrm{OR}=0.52 ; 95 \%$ CI 0.30 to 0.91 ) or $\mathrm{NDF}$ ( $\mathrm{OR}=0.51 ; 95 \%$ CI 0.32 to 0.83 ) were less likely to consume alcohol. Compared with females whose mothers were DF, those whose mothers were NDA ( $\mathrm{OR}=0.23 ; 95 \%$ CI 0.09 to 0.60$)$ were less likely to consume alcohol. For females, parental drinking behaviours had a greater influence on drinking behaviours than did parental attitudes. In addition, cohort 2 was more likely to consume alcohol than cohort 1 ( $\mathrm{OR}=1.84 ; 95 \%$ CI 1.38 to 2.56$)$. Female students were more likely to have consumed alcohol over the last month when their first alcohol use occurred before age $13(\mathrm{OR}=2.26$; 95\% CI 1.69 to 3.03$)$, when perceived negative alcohol expectancies increased one point $(\mathrm{OR}=0.93 ; 95 \%$ CI 0.89 to 0.97$)$, when alcohol refusal efficacies were one point lower $(\mathrm{OR}=0.93 ; 95 \%$ CI 0.90 to 0.95 ), when the perceived number of peers who used alcohol was greater $(\mathrm{OR}=1.49 ; 95 \%$ CI 1.27 to 1.76) and peer pressure with regard to alcohol use by peers was stronger $(\mathrm{OR}=1.24 ; 95 \%$ CI 1.05 to 1.48$)$.

\section{DISCUSSION}

In this study, we found that although the percentage of students who had used alcohol in the last month did not 
Table 4 Logistic regression analysis of adolescent drinking behaviour across gender with regard to parental drinking behaviours and attitudes as well as others factors

\begin{tabular}{|c|c|c|c|c|c|c|}
\hline \multirow[b]{2}{*}{ Variable } & \multicolumn{3}{|c|}{ Males } & \multicolumn{3}{|c|}{ Females } \\
\hline & OR & $95 \% \mathrm{Cl}$ & p Value & OR & $95 \% \mathrm{Cl}$ & p Value \\
\hline \multicolumn{7}{|l|}{ Perceived paternal drinking behaviour/attitude } \\
\hline NDA vs DF & 0.27 & 0.16 to 0.46 & $\star * \star *$ & 0.52 & 0.30 to 0.91 & * \\
\hline NDF vs DF & 0.61 & 0.39 to 0.94 & * & 0.51 & 0.32 to 0.83 & ** \\
\hline DA vs DF & 0.44 & 0.23 to 0.85 & * & 0.47 & 0.22 to 1.01 & \\
\hline \multicolumn{7}{|l|}{ Perceived maternal drinking behaviour/attitude } \\
\hline NDA vs DF & 0.43 & 0.16 to 1.17 & & 0.23 & 0.09 to 0.60 & ** \\
\hline NDF vs DF & 0.47 & 0.18 to 1.25 & & 0.49 & 0.20 to 1.25 & \\
\hline DA vs DF & 0.72 & 0.15 to 3.41 & & 0.58 & 0.13 to 2.50 & \\
\hline \multicolumn{7}{|l|}{ Cohort } \\
\hline 2 vs 1 & 1.51 & 1.15 to 1.98 & ** & 1.84 & 1.38 to 2.56 & $\star \star \star \star ~$ \\
\hline \multicolumn{7}{|l|}{ Age at first alcohol use } \\
\hline$<13$ vs $\geq 13$ years & 2.16 & 1.63 to 2.88 & $\star \star \star \star ~$ & 2.26 & 1.69 to 3.03 & 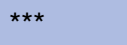 \\
\hline \multicolumn{7}{|l|}{ Residential area } \\
\hline Hsinchu county vs Taipei & 1.01 & 0.76 to 1.35 & & 1.07 & 0.80 to 1.44 & \\
\hline \multicolumn{7}{|l|}{ Parental marital status } \\
\hline Married, living together vs other & 1.19 & 0.72 to 1.98 & & 0.66 & 0.43 to 1.03 & \\
\hline \multicolumn{7}{|l|}{ Paternal education level } \\
\hline Middle school or below vs college or above & 1.28 & 0.79 to 2.08 & & 1.40 & 0.83 to 2.36 & \\
\hline High school vs college or above & 1.30 & 0.91 to 1.85 & & 1.27 & 0.87 to 1.84 & \\
\hline \multicolumn{7}{|l|}{ Maternal education level } \\
\hline Middle school or below vs college or above & 0.95 & 0.58 to 1.58 & & 0.72 & 0.41 to 1.25 & \\
\hline High school vs college or above & 0.91 & 0.64 to 1.29 & & 0.71 & 0.49 to 1.03 & \\
\hline \multicolumn{7}{|l|}{ Parenting behaviour } \\
\hline Degree of emotional support (6-24 points) & 1.01 & 0.97 to 1.04 & & 1.02 & 0.99 to 1.06 & \\
\hline Degree of behavioural supervision (4-16 points) & 1.01 & 0.96 to 1.07 & & 0.96 & 0.91 to 1.01 & \\
\hline \multicolumn{7}{|l|}{ Cognitive factors } \\
\hline Positive alcohol expectancies (5-20 points) & 1.10 & 1.05 to 1.16 & $\star \star \star \star ~$ & 1.02 & 0.97 to 1.08 & \\
\hline Negative alcohol expectancies (5-20 points) & 0.92 & 0.88 to 0.96 & 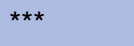 & 0.93 & 0.89 to 0.97 & $* * *$ \\
\hline Alcohol refusal efficacy (5-25 points) & 0.96 & 0.94 to 0.98 & 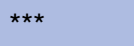 & 0.93 & 0.90 to 0.95 & $\star \star \star \star ~$ \\
\hline \multicolumn{7}{|l|}{ Peer factors } \\
\hline Peer alcohol use (2-10 points) & 1.81 & 1.57 to 2.10 & 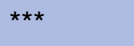 & 1.49 & 1.27 to 1.76 & $* * *$ \\
\hline Alcohol use peer pressure (2-12 points) & 1.45 & 1.26 to 1.66 & 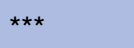 & 1.24 & 1.05 to 1.48 & * \\
\hline
\end{tabular}

differ by gender, the influence of parental drinking behaviours and attitudes on adolescent drinking behaviour depended on both parent and adolescent gender. Paternal, but not maternal, drinking behaviour and attitude influenced male adolescent drinking behaviour, and this influence was significant when fathers were against drinking. Paternal drinking behaviour, and maternal drinking behaviour and maternal attitude, influenced female adolescents' drinking behaviour; in particular, having a non-drinking father or a non-drinking mother significantly influenced the likelihood of adolescent drinking. Specific results are discussed below.

\section{Gender differences with regard to adolescent drinking} behaviour

Compared with males, females have smaller body volumes, less body water content and lower alcohol dehydrogenase activity, and therefore are more likely to have adverse reactions to alcohol, and consequently more likely to refuse alcohol. ${ }^{34}{ }^{35}$ Furthermore, people in Asian societies generally hold negative opinions of female alcohol use, which is more restricted in Asia than in western countries; as a result, Asian females are less likely to drink than Asian males. ${ }^{35}$ Although the bivariate analysis conducted in this study showed that males were more likely to drink than females, the effect of gender disappeared after social learning factors associated with drinking behaviours were controlled for. These results suggest that gender differences in adolescent drinking behaviours operate through the influences of social and environmental variables, such as the behaviours and attitudes of parents and peers.

\section{Influences of parental drinking behaviours and attitudes} on the drinking behaviours of children

Research on the relationship between drinking and health has generated conflicting results. The American Heart Association indicates that although consumption 
of a small amount of alcohol may be beneficial for health, the advantages, disadvantages and risks associated with drinking demand careful assessment, and infrequent alcohol use is recommended. ${ }^{36}$ Adult consumption of a small amount of alcohol is generally considered acceptable. The role of parents is complicated with regard to alcohol use among children.

To the best of our knowledge, no previous study has explored the simultaneous effects of parental drinking behaviours and attitudes on adolescent drinking behaviour. Most previous studies have indicated that parents who drink are less likely to establish rules against drinking for their children. In the current study, we found that drinking parents' negative attitudes towards underage drinking had a mitigating effect on adolescent drinking behaviour. These results indicate that parents' rules for their children's drinking have a stronger influence than their actual drinking behaviours. ${ }^{5}{ }^{19}$ Perceived parental attitudes towards adolescent drinking might reflect drinking rules parents set for themselves and the degree to which they communicate with adolescents about drinking. Previous studies have shown that parents who have more-relaxed attitudes towards drinking have fewer alcohol-related discussions than do parents who have strict attitudes towards drinking. ${ }^{18}$ When the frequency of communication between parents and their children about alcohol use is high, children are less likely to exhibit problematic drinking behaviours. ${ }^{37}$ In addition, strict restrictions on alcohol help to reduce its consumption by adolescents. ${ }^{38}$ Therefore, the results of the current study regarding whether the anti-drinking attitudes of drinking fathers reduce the likelihood of adolescent alcohol use through the formulation of alcohol-use restrictions, through alcohol-related discussions with their children, or through enhanced supervision regarding the drinking behaviour of their children, are worthy of continued investigation. Regardless of whether parents consume alcohol, they must communicate their negative attitudes towards underage drinking to their children.

We found that the influences of parental drinking behaviours and attitudes differed somewhat by gender. Male adolescents were influenced only by paternal drinking behaviours and attitudes, and the influence of paternal regulation factors was larger than that of their demonstration factors. However, the influence of these factors among mothers was not obvious. Fathers and mothers influenced their daughters, but only having non-drinking parents showed strong preventive effects against drinking behaviours, suggesting that females were more easily influenced by behaviour demonstrations. Overall, the influences of paternal drinking behaviours and attitudes on adolescent drinking behaviour were significant regardless of gender.

Although the number of female drinkers has recently increased in Taiwan, and societal attitudes towards female alcohol use have become more open, drinking is still considered a male activity, and male drinking is more acceptable to the public than female drinking. ${ }^{39} 40$
In Asian societies, more adult males drink than do adult females, and adult males consume more alcohol. Although mothers directly parent and nurture their children, the current study suggests that the role of fathers should not be ignored with regard to drinking behaviour in our society.

\section{Other factors affecting adolescent drinking behaviour}

In addition to parental drinking behaviours and attitudes, alcohol expectancies, alcohol refusal efficacy, and peer alcohol use were found to be associated with adolescent drinking behaviour in this study. In addition, a cohort effect was also observed: cohort 2 consumed more alcohol than cohort 1 . This result was likely due to differences between the educational materials provided to the two cohorts. In 2001, a new curriculum was introduced in elementary schools in Taiwan. Unlike the previous curriculum, the new one emphasises positive development, including self-awareness, self-efficacy and communication skills. Cohort 1 was taught the new curriculum starting in the first grade, whereas cohort 2 was taught the previous curriculum. Whether the new curriculum reduced the drinking behaviours of cohort 1 requires additional study.

The current study showed that the negative alcohol expectancies and alcohol refusal efficacies of male and female adolescents significantly predicted their drinking behaviours. However, positive alcohol expectancies were not associated with female drinking behaviour. Since their physiology predisposes females to adverse alcohol reactions, ${ }^{33}{ }^{41}$ females consume less alcohol than males. This fact might explain the current results.

This study also showed that the drinking behaviours of peers and peer pressure associated with alcohol significantly influenced underage drinking, regardless of gender, when all possible personal and environmental factors were controlled for. Peers who provide adverse support are the major social group from which adolescents learn and establish health-risk behaviours. ${ }^{15} 31$

This study has some limitations. First, it considered drinking behaviour only over the last month and did not consider the amount or frequency of alcohol use during that time. Second, we considered adolescents' perceptions of parental drinking behaviours and attitudes, rather than parent-reported parental drinking behaviours and attitudes. Nevertheless, the behaviours and attitudes as perceived by adolescents might better reflect the behaviours of adolescents. Finally, this study did not account for the influence of diverse family structures, such as single-parent families.

Despite the aforementioned limitations, this study nevertheless provides new knowledge regarding gender differences in adolescent drinking behaviour. In addition, the study has several strengths. First, the study used a large sample of students, and examined the influences of parental drinking behaviours and parental attitudes about underage drinking on adolescent drinking behaviours. Second, the study simultaneously controlled 
for important variables that influence adolescent drinking behaviours. Third, the study discussed the association between the drinking behaviours of parents and that of their children in an area with a low prevalence of alcohol use. Our conclusions can support the prevention of early age drinking behaviours in other areas.

The results of the current study suggest that strategies for preventing underage drinking should be gender specific. In particular, family-based drinking prevention programmes should emphasise the different roles of fathers and mothers in the drinking behaviours of their sons and daughters.

\author{
Author affiliations \\ ${ }^{1}$ Department of Nursing, Yuanpei University of Medical Technology, Hsinchu, \\ Taiwan \\ ${ }^{2}$ Institute of Population Health Sciences, National Health Research Institutes, \\ Miaoli, Taiwan \\ ${ }^{3}$ Department of Public Health, Chung Shan Medical University, Tai-Chung, \\ Taiwan \\ ${ }^{4}$ Department of Family and Community Medicine, Chung Shan Medical \\ University Hospital, Tai-Chung, Taiwan \\ ${ }^{5}$ Institute of Health Policy and Management, College of Public Health, National \\ Taiwan University, Taipei, Taiwan
}

Acknowledgements The authors would like to thank the Child and Adolescent Behaviours in Long-term Evolution project, funded by the NHRI, for providing data for this study. Language-editing services were provided by Boldface Editors, Inc.

Contributors All authors participated in the study, and read and approved the final manuscript. C-CH designed the study, completed data analysis, and drafted the manuscript. H-YC and D-LL contributed to data interpretation, provided data analysis advice and revised the manuscript. C-CW was responsible for data collection, cleaning and coding. $L-L Y$ initiated the CABLE project and provided critical comments on the manuscript.

Funding Funding for this study was provided by a grant from the National Health Research Institutes (NHRI, HP-090-SC03).

Competing interests None declared.

Patient consent Obtained.

Ethics approval Ethics approval was given in 2001 by the Human Ethics Committee of the National Health Research Institutes, Miaoli, Taiwan; Human Subject Review Board, Number EC9009003.

Provenance and peer review Not commissioned; externally peer reviewed.

Data sharing statement CABLE data is open for application. Please visit http://cable.nhri.org.tw for more information.

Open Access This is an Open Access article distributed in accordance with the Creative Commons Attribution Non Commercial (CC BY-NC 4.0) license, which permits others to distribute, remix, adapt, build upon this work noncommercially, and license their derivative works on different terms, provided the original work is properly cited and the use is non-commercial. See: http:// creativecommons.org/licenses/by-nc/4.0/

\section{REFERENCES}

1. Casswell S, Pledger M, Pratap S. Trajectories of drinking from 18 to 26 years: identification and prediction. Addiction 2002;97:1427-37.

2. McPherson M, Casswell S, Pledger M. Gender convergence in alcohol consumption and related problems: issues and outcomes from comparisons of New Zealand survey data. Addiction 2004;99:738-48.

3. Kuntsche E, Kuntsche S, Knibbe R. et al. Cultural and gender convergence in adolescent drunkenness: evidence from 23
European and North American countries. Arch Pediatr Adolesc Med 2011:165:152-8.

4. Hundleby JD, Mercer GW. Family and friends as social environments and their relationship to young adolescents' use of alcohol, tobacco, and marijuana. J Marriage Fam 1987;49:151-64.

5. Koning IM, Engels RCME, Verdurmen JEE, et al. Alcohol-specific socialization practices and alcohol use in Dutch early adolescents. $J$ Adolesc 2010;33:93-100.

6. Hung CC, Yen LL, Wu WC. Association of parent's alcohol use and family interaction with the initiation of alcohol use by sixth graders: a preliminary study in Taiwan. BMC Public Health 2009;9:172-82.

7. Hendershot CS, MacPherson L, Myers MG, et al. Psychosocial, cultural and genetic influences on alcohol use in Asian American youth. J Stud Alcohol 2005;66:185-95.

8. Yeh MY, Chiang IC. Comparison of the predictors of alcohol use and misuse among Han and aboriginal students in Taiwan. Addict Behav 2005;30:989-1000.

9. Weinberg NZ, Dielman TE, Mandell W, et al. Parental drinking and gender factors in the prediction of early adolescent alcohol use. Int J Addict 1994;29:89-104.

10. Yu J, Perrine MWB. The transmission of parent/adult child drinking patterns: testing a gender-specific structural model. Am J Drug Alcohol Abuse 1997;23:143-65.

11. White HR, Johnson V, Buyske S. Parental modeling and parenting behavior effects on offspring alcohol and cigarette use. A growth curve analysis. J Subst Abuse 2000;12:287-310.

12. Coffelt NL, Forehand R, Olson AL, et al. A longitudinal examination of the link between parent alcohol problems and youth drinking: the moderating roles of parent and child gender. Addict Behav 2006;31:593-605

13. Gundy KV. Gender and intergenerational transmission of alcohol use patterns: an analysis of adult children in Moscow. Subst Use Misuse 2002;37:65-87.

14. Yeh MY. Factors associated with alcohol consumption, problem drinking, and related consequences among high school students in Taiwan. Psychiatry Clin Neurosci 2006;60:46-54.

15. Haugland SH, Holmen TL, Ravndal E, et al. Parental alcohol misuse and hazardous drinking among offspring in a general teenage population: gender-specific findings from the Young-HUNT 3 study. BMC Public Health 2013;13:1140.

16. Kelly AB, O'Flaherty M, Toumbourou JW, et al. Gender differences in the impact of families on alcohol use: a lagged longitudinal study of early adolescents. Addiction 2011;106:1427-36.

17. van der Vorst H, Burk WJ, Engels RC. The role of parental alcohol-specific communication in early adolescents' alcohol use. Drug Alcohol Depend 2010;111:183-90.

18. Komro KA, Maldonado-Molina MM, Tobler AL, et al. Effects of home access and availability of alcohol on young adolescents' alcohol use. Addiction 2007;102:1597-608.

19. van der Vorst $\mathrm{H}$, Engels RC, Meeus W, et al. The impact of alcohol-specific rules, parental norms about early drinking and parental alcohol use on adolescents' drinking behavior. J Child Psycho Psychiatr 2006;47:1299-306.

20. van der Vorst $\mathrm{H}$, Engels RCME, Meeus W, et al. The role of alcohol specific socialization in adolescents' drinking behaviour. Addiction 2005;100:1464-76.

21. Li F, Barrera M Jr, Hops $\mathrm{H}$, et al. The longitudinal influence of peers on the development of alcohol use in late adolescence: a growth mixture analysis. J Behav Med 2002;25:293-315.

22. Li F, Duncan TE, Hops H. Examining developmental trajectories in adolescent alcohol use using piecewise growth mixture modeling analysis. J Stud Alcohol 2001;62:199-210.

23. Ennett ST, Bauman KE, Foshee VA, et al. Parent-child communication about adolescent tobacco and alcohol use: what do parents say and does it affect youth behavior? J Marriage Fam 2001;63:48-62.

24. Hibell B, Guttormsson U, Ahlström S, et al. The 2007 ESPAD Report: substance use among students in 35 European countries. http://www.drugsandalcohol.ie/11930/

25. Centers for Disease Control and Prevention. Trends in the prevalence of selected risk behaviors and obesity for all students National YRBS: 1991-2011. http://www.cdc.gov/healthyyouth/yrbs/ pdf/us summary all trend_yrbs.pdf

26. World Health Organization. Global Status Report on alcohol and health. Geneva: World Health Organization, 2011.

27. Yen LL, Chen L, Lee SH, et al. Child and Adolescent Behavior in Long-term Evolution (CABLE): a school-based health lifestyle study. Promot Educ 2002;(Suppl 1):33-40.

28. Kerr WC, Greenfield TK, Bond J, et al. Age-period-cohort modelling of alcohol volume and heavy drinking days in the US National Alcohol Surveys: divergence in younger and older adult trends. Addiction 2009;104:27-37. 
29. Song EY, Reboussin BA, Foley KL, et al. Selected community characteristics and underage drinking. Subst Use Misuse 2009;44:179-94.

30. Richter M, Leppin A, Nic Gabhainn S. The relationship between parental socio-economic status and episodes of drunkenness among adolescents: findings from a cross-national survey. BMC Public Health 2006;6:289-97.

31. Latendresse SJ, Rose RJ, Viken RJ, et al. Parenting mechanisms in links between parents' and adolescents' alcohol use behaviors. Alcohol Clin Exp Res 2008;32:322-30.

32. Trucco EM, Colder CR, Wieczorek WF. Vulnerability to peer influence: a moderated mediation study of early adolescent alcohol use initiation. Addict Behav 2011;36:729-36.

33. Leigh BC, Stacy AW. Alcohol expectancies and drinking in different age groups. Addiction 2004;99:215-27.

34. Schenker S, Speeg KV. The risk of alcohol intake in men and women: all may not be equal. N Engl J Med 1990;322:27-9.

35. Ely M, Hardy R, Longford NT, et al. Gender differences in the relationship between alcohol consumption and drink problems are largely accounted for by body water. Alcohol Alcohol 1999;34:894-902.
36. American Heart Association. Alcohol and heart health. http://www. heart.org/HEARTORG/Conditions/More/MyHeartandStrokeNews/ Alcohol-and-Heart-Disease_UCM_305173_Article.jsp

37. Mares SHW, van der Vorst $\mathrm{H}$, Engels RCME, et al. Parental alcohol use, alcohol-related problems, and alcohol-specific attitudes, alcohol-specific communication, and adolescent excessive alcohol use and alcohol-related problems: an indirect path model. Addict Behav 2011;36:209-16.

38. Mares SHW, Lichtwarck-Aschoff A, Burk WJ, et al. Parental alcohol-specific rules and alcohol use from early adolescence to young adulthood. J Child Psychol Psychiatry 2012;53:798-805.

39. Wilsnack RW, Vogeltanz ND, Wilsnack SC, et al. Gender differences in alcohol consumption and adverse drinking consequences: cross-cultural patterns. Addiction 2000;95:251-65.

40. Harrison PA, Fulkerson JA, Park E. The relative importance of social versus commercial sources in youth access to tobacco, alcohol, and other drugs. Prev Med 2000;31:39-48.

41. Bloomfield K, Gmel G, Neve R, et al. Investigating gender convergence in alcohol consumption in Finland, Germany, The Netherlands, and Switzerland: a repeated survey analysis. Subst Abus 2001;22:39-53. 